\title{
Novel Silicon Carbide Integrated Power Module for EV application
}

\author{
Bassem Mouawad, Jordi Espina, Jianfeng Li, Lee Empringham, C. Mark Johnson \\ Power Electronics, Machines and Control Group \\ University of Nottingham, University Park Campus \\ NG7 2RD, Nottingham, United Kingdom \\ mark.johnson@nottingham.ac.uk
}

\begin{abstract}
The successful penetration of Electric Vehicles (EVs) into the global automotive markets requires the developments of cost effective, high performance and high integration power electronic systems. The present work is concerned with the structural integration of power electronic converters to meet targets for increased power density, improved electrical performance and reduced cost without compromising thermal performance or reliability for EV applications. In particular, a $\mathrm{SiC}$ power module to integrate multiple functional elements, i.e. semiconductor devices, DC-link capacitors, output filters, current sensing, and gate driver within a single enclosure sharing a common cooling circuit has been designed and fabricated. Electrical test results showed very smooth waveforms of the outputs, verifying the high frequency switching capacity of the fabricated power module.
\end{abstract}

Keywords-Integrated Power Module; Power Electronics; halfbridge; SiC devices, output filter, Power Electronic Packaging, direct cooling

\section{INTRODUCTION}

It is envisaged that over the coming decades, Electric Vehicles (EVs) is one or more variant forms which will achieve substantial penetration into the global automotive markets, particularly for cars and vans. The most significant barrier impeding the commercialization of EVs is currently the cost. In addition, high power density and low system weight are additional requirements for power systems implemented into mobile equipment.

A typical power converter consists of semiconductor power modules, a physically separate DC-link, a separate input and/or output filter, EMI filters, gate drivers, controllers and sensors. Traditionally, each of these entities is designed separately, cooled separately and has its own operational requirements. Such an approach is restrictive: it overlooks the strong interactions between the elements, for example in realizing a converter-wide thermal and electromagnetic design, and cannot take advantage of potential performance gains and space saving from physical integration at "die" level. Furthermore, the interconnection of physically large discrete components makes it difficult to reduce parasitic inductances to an acceptably low level and leads to concentrated thermal sources that are difficult to cool effectively.

This work was supported by the Engineering and Physical Sciences Research Council (EPSRC) National Center for Power Electronics under grant reference EP/K035304/1.
$\mathrm{SiC}$ power devices can be switched at much high frequency than Si counterparts. If they are integrated into power module using the conventional packaging structure, it would lead to dramatically high overshoots during the turn-off/turn-on stages due to parasitic inductance induced by such structure. Therefore, to achieve their full performance with regard to low switching losses and low conduction losses, they can only be used if the module layout is designed with low parasitic inductances and low thermal impedance [1].

Through addressing the challenges described above, a new solution has been presented by the authors [2] for the structural integration of power electronic converters to meet targets for increased power density, improved electrical performance and reduced cost without compromising thermal performance or reliability. The aim is to integrate multiple functional elements, i.e. semiconductor devices, DC-link capacitors, output filters, current sensing, and gate driver within a single enclosure sharing a common cooling circuit. The highly integrated matrix converter package has been reported based on three Single Basic Power Cell (SBPC) unit with an input filtering component enclosed in an integrated direct-substrate jet impingement cooling system that cools the whole system, the power switches and the integrated inductors [2]. The work presented in this paper focuses more on the design, fabrication and characterization of the Single Basic Power Cell (SBPC) unit.

\section{Single B ASIC Power CELl DESIGN}

The design presented in this paper consists of a basic topology circuit. This circuit consists of two level leg or socalled "half H-bridge" configurations using wide bandgap switching devices on each switch position. It will be referred to as Standard Basic Power Cell (SBPC) throughout this paper. This SBPC is formed using two switches and two diodes. It also includes multiple functional elements with an integrated inductor, on the output side that allows first high current density capability [3], and provide internal filtering configurations at source to achieve a clean, overshoot free commutation. Fig. 1 show the electrical circuit and a cross-sectional schematic of the proposed SBPC unit.

The designed SBPC unit consists of the following components:

- Single Direct Bonded Copper (DBC) substrate customdesigned to accommodate the passive and active 
(a)

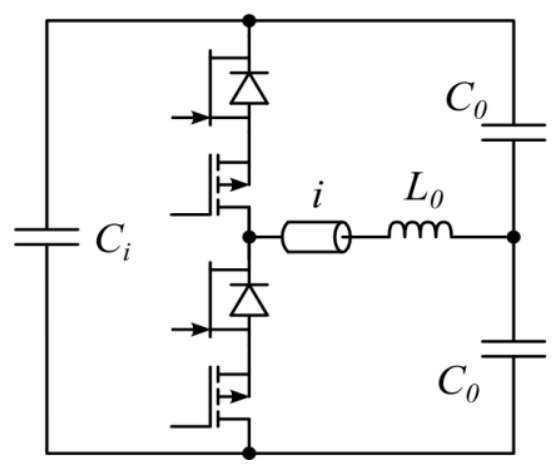

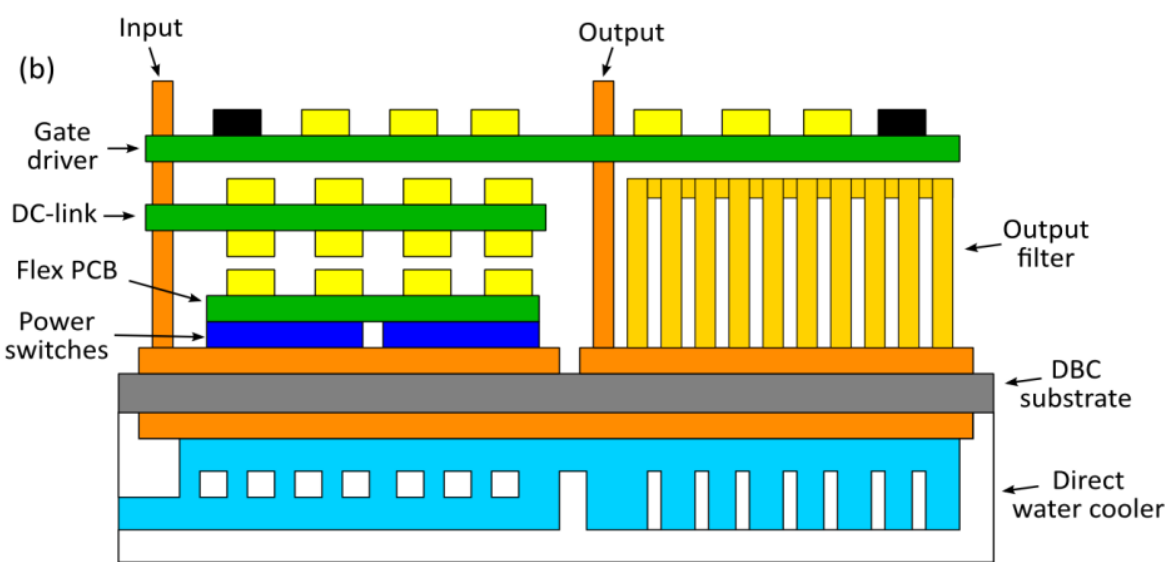

Fig. 1. (a) Single Basic Power Cell (SBPC) circuit and (b) a cross-sectional schematic of the SBPC design placed on direct water cooling system

components. It consists of $0.2 \mathrm{~mm}$-thick copper $(\mathrm{Cu})$ on each side of the ceramic and $1 \mathrm{~mm}$-thick aluminum nitride (AlN) because of its high thermal conductivity compared to other ceramics [4]

- Each switch position of the half H-bridge include four $1.2 \mathrm{kV}$ SiC JFETs which are normally-on devices [5] and four SiC P-MOSFETs (recommended as a direct drive of the JFETs [6]). It should be noted that SiC MOSFETs and $\mathrm{GaN}$ device can be also used in this packaging concept.

- Flex PCB to connect all the power switches together, to replace the $\mathrm{Al}$ wiredbonds as in a conventional power package

- Each SiC JFET switch pair in the designed half H-bridge has its own set of decoupling capacitors placed directly above it on the flex PCB, very close to the commutation loop, to reduce any parasitic inductance

- DC-link capacitors that are populated on a separate PCB and is very close to the commutation loop

- Integrated current sensing at mid-point level

- NTC thermistor to measure the temperature on the DBC substrate

- Integrated inductors on the output side that allows first high current density capability [3], and provide internal filtering configurations to achieve a clean, overshoot free commutation. These inductors are machined from a $\mathrm{Cu}$ bulk to create the desired winding shape, and bonded on the DBC substrate where they are cooled using a shared cooling system

- Custom-designed gate driver placed on top of the assembly

- Pin terminals for the interconnection to provide a lower parasitic inductance than the busbars

- Integrated cooler that allows direct cooling on the backside of the DBC substrate, with two configurations: jet impingement cells [7] to cool down each power switch, and turbulent structure cells to cool down the integrated inductors. The parts of this special enclosure and coolant manifold were made of plastic and manufactured by employing additive manufacture (three dimensional, 3-D printing) technology. The manifold was designed to provide the liquid passageways for coolant passing through mainly by the jet impingement areas, and then the turbulent structure cells.

The advantages of such a package is to significantly reduce electromagnetic emissions compared to the individual elements, volume and weight saving through a shared enclosure and cooling. The three phase converter with the three SBPC and the input filtering components and the shared integrated cooling system are shown in [2]. This paper focuses more on the fabrication of the SBPC unit.

\section{FABRICATION OF THE SBPC UNIT}

\section{A. Assembly process}

Silver (Ag) sintering was chosen for the topside die interconnects because it has higher thermal conductivity and improved reliability than solder [8]. Furthermore, since the melting temperature after sintering $\left(960{ }^{\circ} \mathrm{C}\right)$ is higher than the sintering temperature $\left(\leq 260^{\circ} \mathrm{C}\right)$, multiple assembling processes can be done without affecting the previously-sintered joints. The inductors, the NTC thermistor, the current sensor, the PMOSFETs and the pin terminals are bonded onto the DBC substrate using soldering alloy.

The Al top metal of the as-received $1.2 \mathrm{kV} \mathrm{SiC} \mathrm{JFETs} \mathrm{was}$ first coated with $\mathrm{Ti}$ and $\mathrm{Au}$, using e-beam evaporation through a shadow mask, to provide a suitable surface for sintering. The die attach to the DBC substrate was accomplished with higher melting point solder alloy. The assembling process for constructing the designed SBPC unit module is described as follows:

1) Stencil print pressure-assisted nano-silver paste on the flex $P C B$

2) Dry the paste in the oven @ $130^{\circ} \mathrm{C}$ for $30 \mathrm{~min}$

3) Sinter the topside of the SiC JFETs, on the flex PCB using a die bonder for accurate positioning and for sintering. 

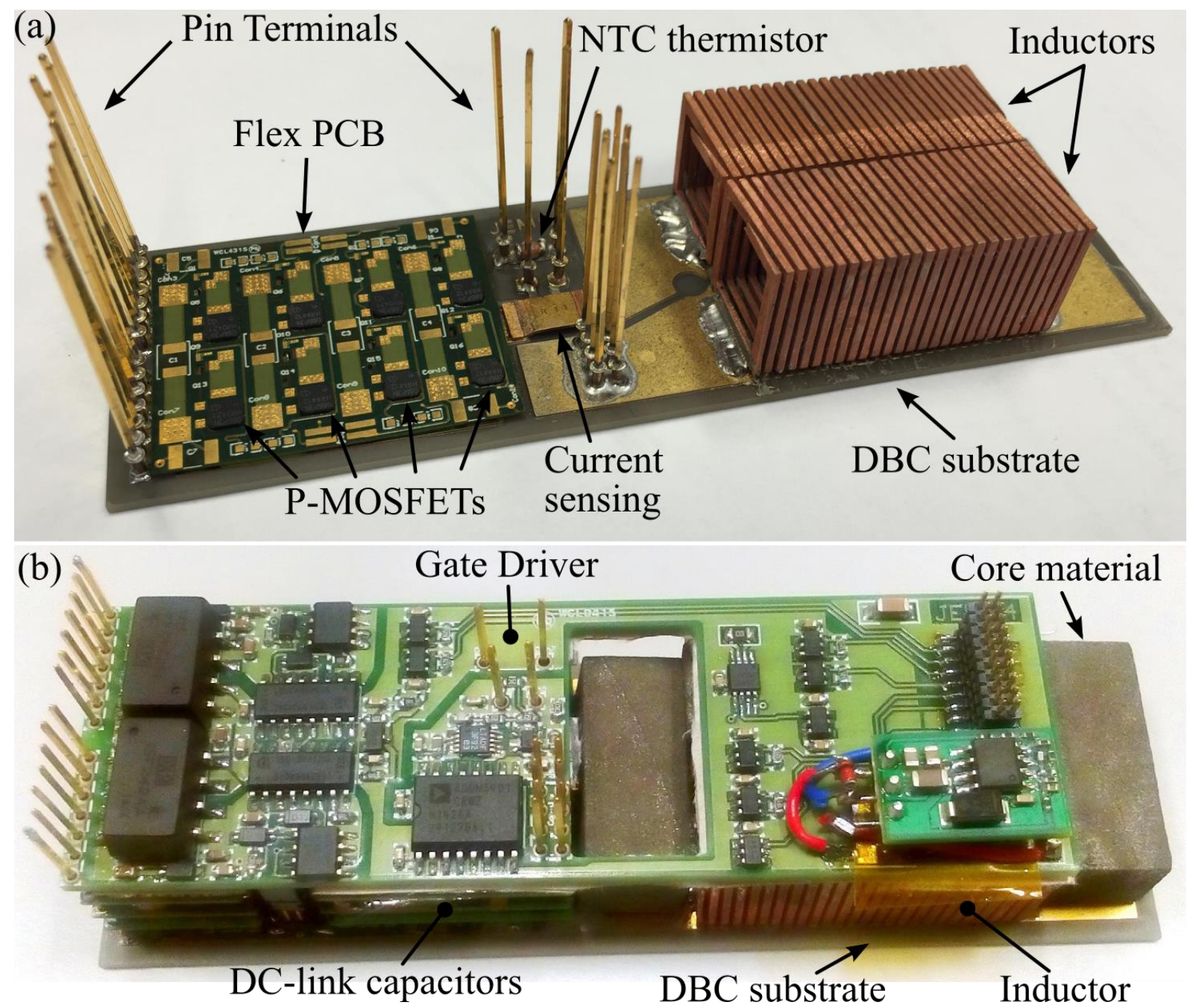

Fig. 2. (a) Photo showing the Flex PCB, the P-MOSFETs, the Pin terminal, the NTC thermistor, the current sensing and the inducotrs assembled on the DBC substrate and (b) the fully assembled SBPC unit

The sintering process was performed at $250^{\circ} \mathrm{C}, 10 \mathrm{MPa}$ for 2 min.

4) Bond the bottom side of the SiC JFETs which are already sintered on the flex, to a DBC substrate using solder alloy $(\mathrm{SnAgCu})$ with higher metling point

5) Bond SiC P-MOSFETs, the inductors, the NTC thermistors, the current sensor, the input/output pin terminals on the DBC substrate using solder alloy $(\mathrm{Sn} 37 \mathrm{~Pb})$ with lower melting point. Fig. 2 a shows the SBPC package at this stage.

6) At the same time, all the DC-link capacitors are soldered on a separate PCB. The decoupling capacitors are manually soldered on its corresponding position on the Flex $P C B$

7) Insert the core material between the windings of the inductors

8) Mount the DC-link capacitors and the gate driver on the topside as shown in Fig.2b.

\section{B. X-ray imaging}

The bonding position of each SiC JFET was examined nondestructively using X-ray system. This was carried out on a Zeiss Xradia Versa-XRM500 CT system. X-ray projection images

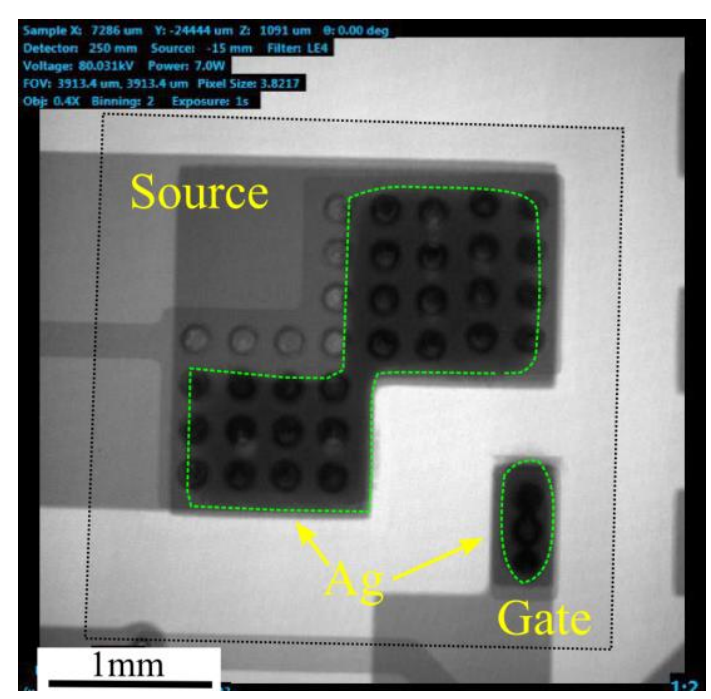

Fig. 3. X-ray projection image showing one SiC JFET (dashed line in black) sintered on the flex PCB. The silver areas at the gate and the source pad are shown in yellow. 
were performed for all the devices once sintered on the flex PCB. Fig. 3 shows the projection image of one sintered SiC JFET showing the Ag areas at the gate and the source pad with spatial resolution of $\sim 3.8 \mu \mathrm{m}$. This shows an accurate positioning with no large voids in the bond line of the topside attachment. The Ag paste are confined in its specific area and there is no short-circuit between the gate and source pad. It should be noted that the circular dots that appears in Fig. 3 represents the vias within the flex PCB.

\section{ELECTRICAL EVALUATION}

After the assembling process, the constructed SBPC module was tested to illustrate the electrical performance. Fig. 4 shows the electrical circuit and the corresponding measured waveforms of the SBPC at a switching frequency of $143 \mathrm{kHz}$. The experimental parameters used for the electrical test are listed in Error! Reference source not found.. The SBPC unit was tested in a DC-DC mode where the nominal DC-link input voltage of $190 \mathrm{~V}$ (illustrated in blue in Fig4b) with an output voltage of $\sim 48 \mathrm{~V}$ (illustrated in green in Fig4b).

The voltage waveform at the mid-point of the half-bridge modules and the measured output current are illustrated in Fig4c in black and red, respectively. It should be noted that test is performed with an open loop fixed $29 \%$ duty cycle, hence the poor regulation on the output voltage $\left(\mathrm{V}_{\text {out }}\right)$. Note probe induced
TABLE I. EXPERIMENTAL PARAMETERS

\begin{tabular}{|l|c|}
\hline \multicolumn{2}{|c|}{ Continuous switching test } \\
\hline Drain current $\left(\mathrm{I}_{\mathrm{D}}\right)$ & Type \\
\hline Bus voltage $\left(\mathrm{V}_{\text {bus }}\right)$ & $30 \mathrm{~A}$ \\
\hline Gate voltage $\left(\mathrm{V}_{\text {gate }}\right)$ & $190 \mathrm{~V}$ \\
\hline Duty cycle & $+3 \mathrm{~V} /-18 \mathrm{~V}$ \\
\hline Switching frequency & 0.29 \\
\hline Junction temperature $\left(\mathrm{T}_{\mathrm{j}}\right)$ & $\begin{array}{c}143 \mathrm{kHz} \\
\text { temperature })\end{array}$ \\
\hline
\end{tabular}

noise is present on the output current $\left(\mathrm{I}_{\text {out }}\right)$ waveforms are shown in Fig4c and has been filtered for display purposes.

One can see the clean switching edges across $V_{D S}$, with no discernible overshoot and minimal ringing, highlighting the effective integration of the input capacitors and creation of the low inductance commutation loop. The power level tested (about $1.5 \mathrm{~kW}$ ) is lower than the rated power because the objective of this work is to verify the high switching capability of the SBPC unit.

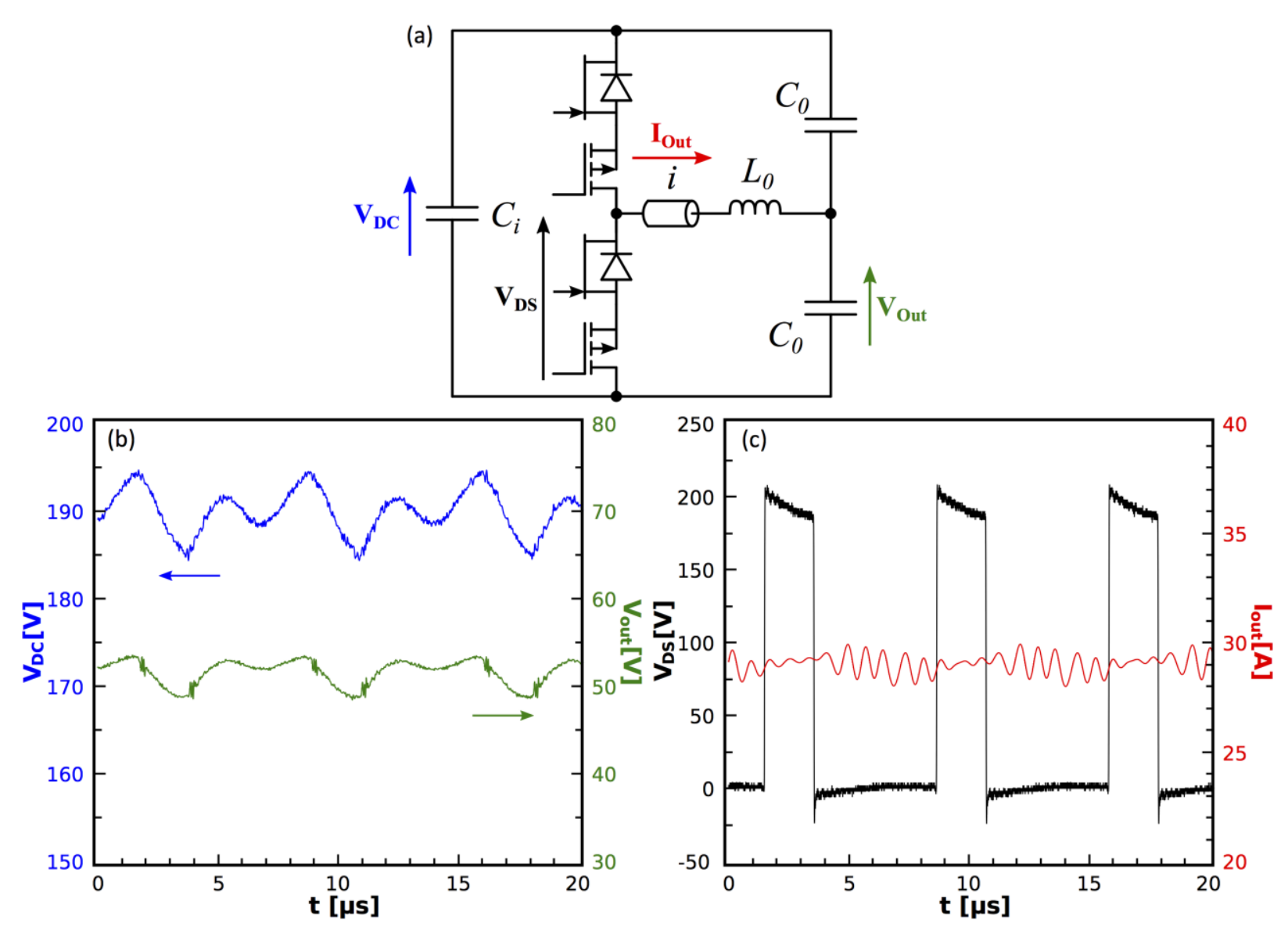

Fig. 4. (a) Electrical circuit and (b) \&(c) the corresponding measured waveforms of the designed module at a switching frequency of $143 \mathrm{kHz}$ 
It should be noted that the SBPC includes filters aiming to filter the high frequency harmonics (values are Lo $=25 \mu \mathrm{H}$ and Co $=1.8 \mu \mathrm{F}$ ). The advantages of including filters inside the power module are numerous: the power converter system can be made to be more compact, preventing propagation of harmonics and EMI, while from an electrical machine perspective, the levels of damaging high speed common mode voltage (CMV) are drastically reduced, increasing the electrical machine's lifetime.

\section{CONCLUSION}

This paper presents the design, assembling process, and electrical switching test of a highly integrated fully $\mathrm{SiC}$ power module for Electric Vehicles (EV) application. The concept is based on a fully integration of all the components including the power switches, DC-link capacitors, output filter, gate driver and current sensing in one Single Basic Power Cell (SBPC) unit.

The assembling process of the SBPC has then been presented in detail using silver sintering interconnects and the flex PCB assembled onto a DBC substrate. Embedded output filter components are also assembled on the same DBC substrate enabling to be cooled using a shared cooling system with the power switches. An electrical switching test at a switching frequency of $143 \mathrm{kHz}$ was carried out to evaluate the electrical performance of the designed and assembled IPM. This shows a clean switch with no discernible overshoot and minimal ringing, highlighting the effective low inductance design. Further work, the electrical test will be performed at the rated power level of the integrated power module for high power density application.

\section{ACKNOWLEDGMENT}

Authors would like to acknowledge Dr. Bezhad Ahmadi and Dr. Liliana De Lillo for the valuable discussion and technical support. Authors are grateful to Dr. Robert Skuriat for designing the cooling system. This work is supported by the Vehicle Electrical Systems Integration (VESI) project.

\section{REFERENCE}

[1] L. Empringham, L. De Lillo, and M. Schulz, "Design Challenges in the Use of Silicon Carbide JFETs in Matrix Converter Applications," IEEE Trans. Power Electron., vol. 29, no. 5, pp. 2563-2573, 2014.

[2] J. Espina, B. Ahmadi, L. Empringham, L. De Lillo, and M. Johnson, "Highly-Integrated Power Cell for High-Power Wide Band-gap Power Converters," in IEEE 3rd International Future Energy Electronics Conference and ECCE Asia (IFEEC 2017 - ECCE Asia), 2017.

[3] R. Saeed, C. M. Johnson, L. Empringham, and L. De Lillo, "High current density air cored Inductors for direct power module integration," in 16th European Conference on Power Electronics and Applications (EPE'14ECCE Europe), 2014, pp. 1-6.

[4] W. W. Sheng and R. P. Colino, Power electronic modules, design and manufacture. CRC press, 2005.

[5] “CoolSiC ${ }^{\mathrm{TM}} 1200 \mathrm{~V}$ SiC JFET IJW120R100T1," Infineon, 2013. [Online]. Available: http://www.infineon.com/dgdl/InfineonIJW120R100T1-DS-v02_00en.pdf?fileId=db3a304341e0aed001420353f03a0e4b.

[6] R. Siemieniec and U. Kirchner, "The 1200V Direct-Driven SiC JFET power switch," in 14th European Conference on Power Electronics and Applications (EPE 2011), 2011, pp. 1-10.

[7] C. M. Johnson, A. Castellazzi, R. Skuriat, P. Evans, J. Li, and P. Agyakwa, "Integrated High Power Modules," in 7th International Conference on Integrated Power Electronics Systems (CIPS), 2012, pp. 357-366.

[8] X. Cao, T. Wang, K. D. T. Ngo, and G. Q. Lu, "Characterization of leadfree solder and sintered nano-silver die-attach layers using thermal impedance," IEEE Trans. Components, Packag. Manuf. Technol., vol. 1, no. 4, pp. 495-501, 2011. 